\title{
The Protective Role of Couple Communication in Moderating Negative Associations Between Financial Stress and Sexual Outcomes for Newlyweds
}

Jocelyn S. Wikle

Brigham Young University - Provo

Chelom E. Leavitt

Brigham Young University - Provo

Jeremy B. Yorgason

Brigham Young University - Provo

Jeffrey P. Dew

Brigham Young University - Provo, jeff_dew@byu.edu

Heather M. Johnson

Follow this and additional works at: https://scholarsarchive.byu.edu/facpub

\section{Original Publication Citation}

Wikle, J.S., Leavitt, C.E., Yorgason, J.B. et al. The Protective Role of Couple Communication in Moderating Negative Associations Between Financial Stress and Sexual Outcomes for Newlyweds. Journal of Family Economic Issues (2020).

\section{BYU ScholarsArchive Citation}

Wikle, Jocelyn S.; Leavitt, Chelom E.; Yorgason, Jeremy B.; Dew, Jeffrey P.; and Johnson, Heather M., "The Protective Role of Couple Communication in Moderating Negative Associations Between Financial Stress and Sexual Outcomes for Newlyweds" (2020). Faculty Publications. 4548.

https://scholarsarchive.byu.edu/facpub/4548 


\title{
The Protective Role of Couple Communication in Moderating Negative Associations Between Financial Stress and Sexual Outcomes for Newlyweds
}

\author{
Jocelyn S. Wikle ${ }^{1}$ D $\cdot$ Chelom E. Leavitt ${ }^{1}$. Jeremy B. Yorgason ${ }^{1} \cdot$ Jeffrey P. Dew ${ }^{1} \cdot$ Heather M. Johnson ${ }^{2}$
}

Accepted: 8 October 2020

○) Springer Science+Business Media, LLC, part of Springer Nature 2020

\begin{abstract}
This study longitudinally examined the sexual costs of economic distress in newlywed couple relationships. Family stress theory posits an association between economic pressure and family relationships. The ability of financial strain to contaminate non-financial aspects of a marriage is troubling considering that many newlyweds report difficulty with financial adjustments after marriage. Positive communication may be a skill that enables young couples to alleviate economic pressure, and the study evaluated the moderating roles of financial communication, sexual communication, and relational communication. Utilizing an actor-partner interdependence moderation model, hypotheses were tested using dyadic data from 2044 couples from a nationally representative sample of newlywed couples in 2017-2018 in the United States. We found that economic pressure of both partners negatively associated with their own contemporaneous sexual satisfaction, but not their partner's. In addition, we found weak links over time for wives only. Financial communication attenuated the negative effects when husbands and wives experienced economic pressure. Financial communication by a partner protected against negative sexual consequences for wives when that partner experienced economic pressure. Additionally, strong financial communication by wives protected wives from negative sexual consequences of their husbands' economic pressure. The findings align with family stress theory; specifically, communication may be a resource that helps couples adapt to negative financial stress.
\end{abstract}

Keywords Sex $\cdot$ Financial stress $\cdot$ Financial communication $\cdot$ Sexual communication $\cdot$ Sexual satisfaction $\cdot$ Gender differences

\section{Introduction}

Establishing a mutual understanding regarding money and sex is one of the most important tasks newly-married couples face. Both financial and sexual factors show strong links

This is one of several papers published together in Journal of Family and Economic Issues on the "Special Issue on Couples, Families, and Finances".

Electronic supplementary material The online version of this article (https://doi.org/10.1007/s10834-020-09728-2) contains supplementary material, which is available to authorized users.

Jocelyn S. Wikle

wikle@byu.edu

1 School of Family Life, Brigham Young University, Provo, UT, USA

2 Riverton, UT, USA to marital outcomes such as marital satisfaction or instability (Hill et al. 2017; Leavitt et al. 2019). Recent research suggests that marital issues surrounding finances and sex are correlated (Leavitt et al. 2019), though study of this specific association is in its infancy. The ability of financial strain to persist and contaminate non-financial aspects of a marriage is troubling considering that many newlyweds report difficulty with financial adjustments after marriage (Fox and Bartholomae 2000). The newlywed period is a critical transitional juncture as a couple establishes family financial practices while also developing their sexual relationship (Huston et al. 2001). Financial stress experienced early in marriage links with increased marital instability up to three years later (Barton and Bryant 2016), suggesting that financial difficulties experienced early in marriage may have long-term ramifications for couples.

Mechanisms moderating links between economic pressure and sex remain important to understand, considering couples' comfort and satisfaction in sexual domains have 
broad ramifications for couple and family wellbeing. Positive communication is one skill that may enable young couples to alleviate problems within their relationship (Litzinger and Gordon 2005). Although financial communication is a distinctive form of couple communication (Dew and Dakin 2011), no prior work connects financial communication to sexual outcomes or evaluates how financial communication moderates links between economic pressure and sexual outcomes. Other forms of communication, such as relational (Larson et al. 1998) and sexual communication (Rehman et al. 2011) are positively linked to sexual outcomes. However, it is not clear whether these forms of communication ameliorate the negative impacts of economic pressure on sexual outcomes or operate independently.

This study evaluates ramifications of family economic pressure on non-financial family domains. We use dyadic longitudinal data from newlywed couples to evaluate both short-term and long-term associations between couple economic pressure and sexual satisfaction and frequency. Further, this study evaluates whether distinct forms of couple communication moderates economic pressures as they impact couple sexual outcomes, which informs our understanding of how different forms of communication may help couples cope with economic pressure by attenuating negative effects on couple sexual outcomes.

\section{Family Stress Theory}

The family stress framework posits that financial stressors (e.g., job loss, inadequate income) influence family relationships (Conger et al. 1994). In the complete version of the family stress model, financial stressors cause partners to experience a subjective state called economic pressure. Economic pressure, then, represents an affective state of stress and worry over one's finances (e.g., not having sufficient income for one's needs). Economic pressure may lead to more generalized negative affect such as anxiety, depression, and hostility, and the negative affective states spillover and decrease relationship quality (e.g., marital quality or parent-child relationship quality). Scholars have validated the Conger et al. (1994) family stress model in a variety of macroeconomic and microeconomic settings in marriage (Dew 2007; Gudmunson et al. 2007; Kwon et al. 2003), and the family stress model remains paramount in its ability to frame financial and marital quality issues.

We test an abbreviated model that suggests a direct link between economic pressure and marital sexual outcomes, without explicitly measuring the intermediate negative affective states. Although we know of no research that specifically examines economic pressure and sexual well-being, extant literature provides some clues about associations between general stress and sex. Stress associates with lower-quality sexual experiences (Bodenmann et al. 2006; Morokqff and
Gillilland 1993). An increase in stress for either women or men is linked with more sexual problems in the relationship, particularly when the stress includes financial strain (Lau et al. 2005). Stresses surrounding financial issues are particularly deleterious for sex because stress fatigues the individual physically, emotionally, and relationally (Morokqff and Gillilland 1993). Past research also supports a link between economic pressure and general relationship satisfaction. For example, couples higher in materialism felt greater financial stress, which diminished their feelings of satisfaction within the relationship (Dean et al. 2007). Additionally, couples who disagreed about money issues also disagreed about sexual issues (Wheeler and Kerpelman 2016). Financial distress is one element of many that contributes to sexual well-being (del Mar Sánchez-Fuentes et al. 2014).

\section{Contemporaneous and Long-Term Consequences of Economic Pressure for Newlyweds}

Newly married couples are unique as they experience a high rate of change in the early years of their marriage, both within the relationship as well as outside of it (McNulty et al. 2016). The processes used as they encounter new challenges in their marriage establish the foundations of their financial, sexual, and communicative patterns as well as marital stability. These patterns launch couples onto relationship trajectories (Lavner and Bradbury 2010; Williamson and Lavner 2019) determining both satisfaction and stability outcomes. The appearance of external stressors early in marriage can disrupt marital outcomes. Financial stress in the early years of marriage predicts greater marital instability for both spouses (Barton and Bryant 2016) and correlates with negative communication patterns (Williamson et al. 2013). As negative communication patterns continue, the perception of marital problems and conflict increases causing decreased intimacy and vulnerability (LaMotte et al. 2017), decreased satisfaction (Lavner et al. 2014), and greater instability (Gottman et al. 1998).

Economic pressure may have immediate and long-lasting influences on couple sexual outcomes, and understanding the speed of economic pressure decay provides insight into how couples can navigate economic pressure. Economic pressure may decline over time as a couple's financial situation improves. Additionally, the consequence of economic pressure may resolve as couples learn to manage and cope with economic pressure, even if pressure levels remain unchanged through time. We have very little previous research to guide us in exploring the persistence of economic pressure. Of note is research suggesting that couples feel that financial stressors have longer-lasting effects on their relationship compared to other stressors (Papp et al. 2009). Additionally, Leavitt et al. (2019) found evidence that materialism was negatively associated with husbands' sexual satisfaction 
both contemporarily and longitudinally, demonstrating that financial domains may have long-term consequences for marital sexual relationships. Based on the family stress model and related empirical research, economic pressure may be negatively associated with marital sexual outcomes contemporaneously as well as long-term.

\section{Protecting Relationship Quality}

Although the family stress model provides an understanding of the pathways that link financial stressors and relationship quality, discovering individual and relationship attributes that moderate those pathways is, perhaps, more important. That is, finding individual and relationship attributes that can help couples weather the storms of economic pressure would greatly benefit couples. Consequently, in addition to testing the association between economic pressure and marital sexual outcomes, we remain interested in examining potential moderators of this association.

While the family stress model itself does not explicitly consider potential moderators that may protect couples facing economic pressure, closely related models-such as the family adjustment and adaptation response model (FAAR; Patterson 2002)—do countenance such moderators. The FAAR model suggests that individual resources and relationship resources may help couples to experience bonadaptation, or family relationship growth, because of the stressing experience (Patterson 2002; Dew et al. 2018). At a minimum, resources may help couples maintain their relationship in the face of economic pressure. Indeed, Conger et al. (1999) and his colleagues themselves investigated moderators of the family stress model and found that couple problem solving and mutual support for each other helped couples maintain their marital quality despite economic pressure (Conger et al. 1999).

Scholars have recently examined additional moderators. Furthermore, in a more explicit test of the FAAR model and the process of bonadaptation, another study found that religious marital sanctification, social support, financial support, and relationship maintenance behaviors helped married couples use the stress of the 2007-2009 Recession to build their marital commitment (Dew et al. 2018). Healthy communication importantly helps couples in their relationship (Litzinger and Gordon 2005), and our careful consideration of its moderating role provides additional insight into its protective influence.

\section{Financial Communication and Sexual Satisfaction}

Couples report patterns of financial communication which are distinct from other communication (Dew and Dakin 2011). Financial communication remains difficult, even among couples reporting strong relational communication, and couples often avoid financial conversations (ZmyslinskiSeelig 2016). Despite an understanding that finances cause many marital disillusions (Dew and Dakin 2011), little is known about the consequences of financial communication on general relationship quality (Romo 2013). Some research suggests that negative financial communication can increase relationship distress (Randles 2014; Wilmarth et al. 2014; Zimmerman and Roberts 2012) while positive financial communication can improve relationship quality (Skogrand et al. 2011; Zimmerman and Roberts 2012). On the other hand, some couples believed that restricting their financial communication helped preserve relationships by avoiding senseless financial conflict (Romo 2013). In sum, current financial communication knowledge and general relationship quality remains limited and presents mixed findings. Although Romo (2015) suggested that financial communication with a partner may interact with economic pressure to benefit couple relationships, this moderator has not been tested previously. We know of no prior research evaluating more specific links between financial communication and couple sexual outcomes.

\section{Sexual Communication and Sexual Satisfaction}

General communication skills are beneficial for a strong relationship, but individuals who are able to communicate about sex, in particular, report higher satisfaction with their sexual lives and better sexual functioning (MacNeil and Byers 2009; Rehman et al. 2011). People who openly communicate about their sexual preferences or fantasies generally feel better about their sexual interactions with their partner (Montesi et al. 2010). In fact, the more types of communication strategies that couples employed the more sexual satisfaction they experienced (Frederick et al. 2017). In an intervention setting, when couples learned to communicate about sexual difficulties their marital satisfaction improved (Chesney et al. 1981), suggesting that sexual communication is a skill couples can develop to enhance their marriages. Past research provides strong agreement that people who communicate their sexual likes and dislikes to their partner are more satisfied with their sex lives. However, it is unclear how sexual communication interacts with economic pressure.

\section{Relational Communication and Sexual Satisfaction}

Good communication has a long record of positive associations with satisfying romantic relationships (Litzinger and Gordon 2005) and satisfying sexual relationships (Mark and Jozkowski 2013). Daily and overall intimacy in the relationship improve when both self-disclosure and partner disclosure are perceived as open, likely increasing the couple's sexual satisfaction (Laurenceau et al. 2005). 
Both constructive communication and sexual satisfaction contribute to overall marital satisfaction (Litzinger and Gordon 2005) and it is likely that healthy communication patterns and sexual satisfaction influence each other (Yoo et al. 2014). Individuals who can express their needs, desires, and frustrations are likely to better navigate the complexities of an intimate romantic and sexual relationship. In fact, in relationships where couples struggle to resolve marital conflicts through normative processes of marital communication, the couple's sex life is negatively impacted (Metz and Epstein 2002). When couples are taught constructive communication within an intervention setting, the increased marital communication was accompanied by increased satisfaction with the relationship (Markman et al. 1993). Couples struggling with sexual dysfunction were found to exercise poor communication which was then connected to a decrease in sexual satisfaction (Haning et al. 2007).

\section{Gendered Aspects of Finances, Sex, and Communication}

A final area we address is gender differences and similarities in finances, sex, and communication in couples. Men and women may face different circumstances or may process their circumstances differently (Conger et al. 1993). In considering gender differences in finances, Thoits (1987) posited that men were more negatively affected by financial problems than women. Moreover, Anand et al. (2008) found that men experience more financial stress than women of the same age, suggesting that husbands may be particularly vulnerable to economic pressure. Men may be particularly influenced by economic pressure, as men may be less able to detach their identity as providers, allowing financial stress to define experiences more broadly (Morokqff and Gillilland 1993), whereas women may more easily separate financial stress from other aspects of their lives. For sexual outcomes, materialism was associated with less sexual satisfaction for cohabiting and married men, but was associated with greater sexual satisfaction for women (Leavitt et al. 2019). Sexual communication appears to be important for both men and women; individuals who disclose their own thoughts and desires about sex showed associations with their own satisfaction (Rehman et al. 2011). In reality, communication facilitates an emotional connection that is intertwined with sexual intimacy (Yoo et al. 2014) and appears to be important for both men and women.

Couples make up an interconnected system where experiences in people's lives can reverberate and have disruptive effects on their partners. On one hand, partners may help buffer negative experiences and on the other hand, a high level of connectedness could lead to high levels of negative spillover from a spouse experiencing difficulty (Timmons et al. 2017). These partner effects may not be symmetric due to gendered differences in how husbands and wives respond to each other. In terms of finances, past research links husband's financial stress to wives' emotional health (Rook et al. 1991). Likewise, wives' financial stress has been linked to lower husbands' warmth in the relationship (Ross et al. 2017). However, husbands' relationship maintenance behaviors, such as showing affection, helped their wives maintain a higher level of marital satisfaction and a lower level of thoughts of divorce when wives were experiencing economic pressure (Dew and Jackson 2017). Past research has documented that young adult women often cope with stress (including financial stress) by expressing feelings and seeking emotional support while young adult men employ strategies such as disengagement (Brougham et al. 2009). Partners, therefore, may differentially benefit from communication, considering differences in how men and women use communication and emotional support to help with financial stress. Past research suggests strong partner relational communication affects husband's sexual outcomes and wives' sexual outcomes in similar ways (Yoo et al. 2014). Sexual communication, on the other hand, appears to vary by gender. Sexual communication has important partner effects for husbands as they benefit from their partner's disclosers of sexual desires (Rehman et al. 2011). Men may gain additional satisfaction when they know that their partner is engaged and/or enjoyed the sexual experience.

Gender differences in how spouses experience economic pressure and potential differences in how economic pressure shapes actors and partners motivate our study of both actors and partners (Kenny et al. 2006) to better understand nuanced differences in how husbands and wives respond to economic pressure and utilize communication to maintain healthy sexual relationships.

\section{Current Study}

This study uses dyadic longitudinal data from married couples to evaluate both short-term and long-term ramifications of couple economic pressure on sexual satisfaction and frequency. Further, this study evaluates whether distinct forms of couple communication contemporaneously moderate economic pressure as it impacts couple sexual outcomes. Considering important gender differences in how partners respond to economic pressure and communicate, we propose an actor-partner interdependence moderation model (APIMoM; Garcia et al. 2015; Kenny et al. 2006) to examine associations of economic pressure with the outcomes of sex satisfaction and frequency. This model includes the moderating roles of financial communication, sexual communication, and general communication. Figure 1 provides a succinct conceptualization of the longitudinal model, and 


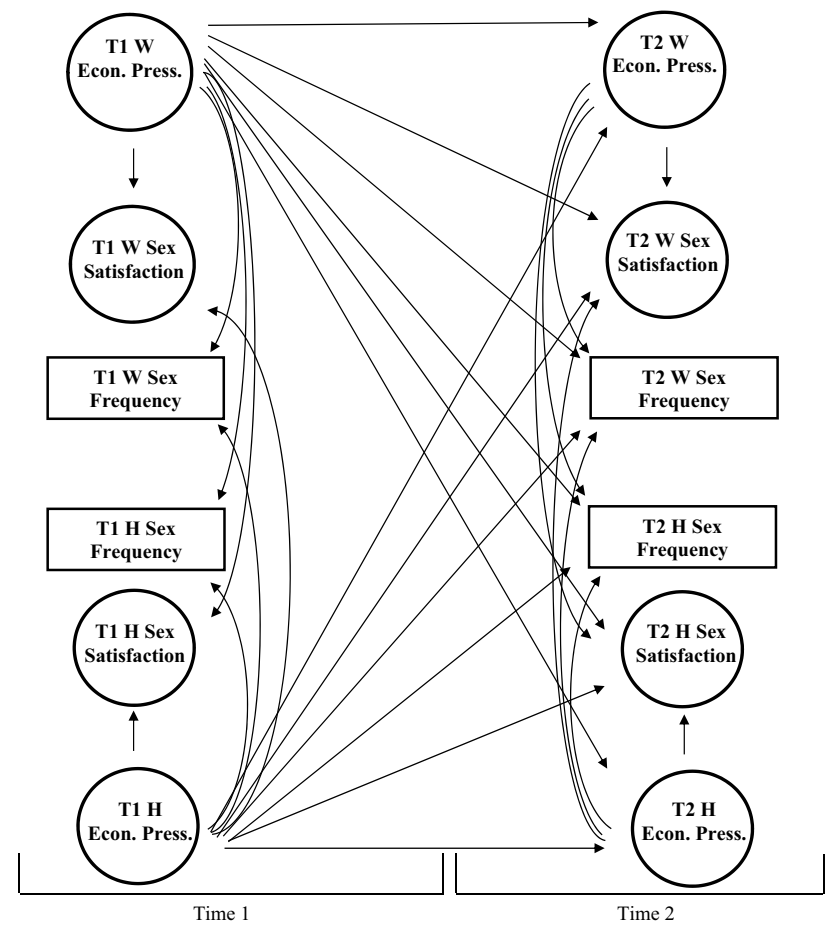

Fig. 1 Conceptual model of actor-partner connections when testing associations between economic pressure and sexual outcomes over time. To simplify presentation and increase clarity, predicting pathways from sexual outcomes at $\mathrm{T} 1$ to sexual outcomes at $\mathrm{T} 2$ were estimated but are not shown

Fig. 2 provides a visualization of the contemporaneous moderation model.

With the potential for economic pressure to be a longlasting source of strain (Papp et al. 2009), and based on past research finding links between finances and sexual interactions (Hill et al. 2017; Wheeler and Kerpelman 2016), we broadly hypothesize a negative association between economic pressure and sexual interaction, including contemporaneous associations and longitudinal associations up to 1 year (H1). Prior research finds positive effects of sexual communication (Rehman et al. 2011), and relational communication (Mark and Jozkowski 2013) on couple sexual outcomes. Additionally, we rely on research showing that financial communication improves relational quality (Skogrand et al. 2011; Zimmerman and Roberts 2012), which is likely true for sexual outcomes as well. Therefore, we broadly hypothesize that these three forms of communication will be protective against the negative effects of economic pressure on sexual outcomes (H2). Prior research finds that own and partner relational communication may be more helpful for wives than husbands to relieve financial stress (Brougham et al. 2009; Dew and Jackson 2017) and past research points to benefits of strong partner sexual communication for husbands (Rehman et al. 2011). We therefore hypothesize that gender will play an important role in actor

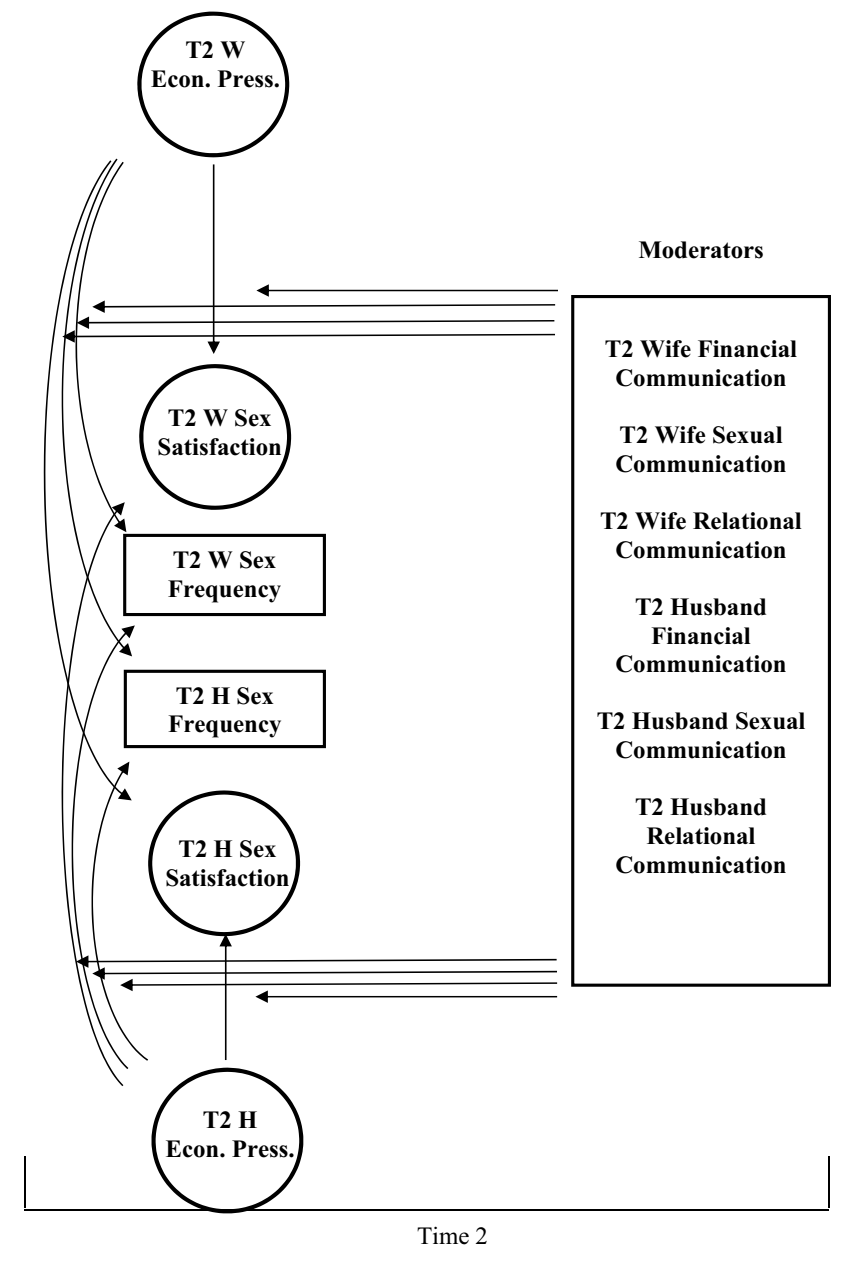

Fig. 2 Conceptual model of actor-partner connections when testing communication moderators of associations between economic pressure and sexual outcomes

and partner effects, suggesting that we will not find structural invariance in our longitudinal model (H3).

\section{Method}

\section{Data and Sample}

The sample for the study came from the CREATE study (Yorgason et al. 2018), a longitudinal nationally representative study of newlyweds in the United States that started in 2016. Participants were recruited using first a cluster sampling of 239 counties, then random sampling from recent marriage certificates within each county. To be eligible for inclusion in the study, at least one partner needed to be between 18 and 36 years of age, living in the US, and one partner marrying for the first time.

The current analysis is focused on heterosexual continuously married couples from Waves 2 and 3 of the CREATE 
study. The survey did not include measures of economic pressure and financial communication until after Wave 1 of the survey. Consequently, we use the second wave (T1) and third wave (T2) of data to test our theoretical model, which we term Time 1 and Time 2 in the conceptual model. Our analytic sample is somewhat smaller than the full sample at Wave 1 . Of the 2187 couples originally in the sample, 488 couples did not respond to the survey in Wave 3. Couples who didn't respond to the survey in Wave 3 were similar in age, marriage age, and the fraction who had been previously married, compared to couples who participated. Couples who didn't respond during Wave 3 were less likely to be White, had less education, were less likely to be a student during Wave 2, were less likely to be employed full-time during Wave 2, were less likely to be pregnant at Wave 2, and were less likely to be parents at Wave 2, compared to couples who participated. This suggests that individuals who didn't participate in Wave 3 were a non-random group. These couples remained in the sample, and the use of FIML to account for missing data is discussed later in the article. Due to the focus of the paper on couple sexual outcomes, we omitted 78 couples who were not continuously married by Wave 3 . The use of actor-partner analysis with gender interpretations for husbands and wives motivated omitting 73 gay or lesbian couples. Excluded couples and included couples were similar in age, race, ethnicity, and education levels. Excluded couples were more likely to be employed full-time at Wave 2 , less likely to be pregnant at Wave 2, and less likely to be parents at Wave 2. The final sample was 2044 couples. Each partner in our final sample individually answered items in Wave 2 and Wave 3, and measures were answered by both partners in the relationship. Most couples provided full information on all measures; however, 761 couples had at least one missing value on a measure of interest, with most of the non-response occurring on the sexual measures or Wave 3 attrition. The only demographic variables with missing values in the raw data were age and age at first marriage, and all other demographic variables were complete.

Table 1 reports the demographics of the 2044 couples in the final sample. Interestingly, 65\% self-identified as White non-Hispanic, 9\% self-identified as Black non-Hispanic, and $16 \%$ self-identified as Hispanic. Fifty-eight percent of wives had attended some college, with $34 \%$ of all wives holding a bachelor's degree or higher, while $52 \%$ of husbands had attended some college, with $26 \%$ of husbands had a bachelor's degree or higher. Wives who worked full time was $40 \%$ while husbands who worked full time was $58 \%$. Average age at marriage was 26.7 for wives and 28.6 for husbands, with couples being married an average of 3.4 years at Time 2 . Eight percent of the analytic sample were married previously to another partner. Seven percent of wives reported being pregnant at the time of their $\mathrm{T} 2$ interview, with an average of 0.89 children at that time.

\section{Measures}

\section{Dependent Variables}

Two dependent variables measuring couples' sexual outcomes were used. To measure sexual frequency, respondents were asked "How often do you currently have sex with your partner?" Responses answered with a Likert scale ranging from one (never) to seven (more than once a day). This commonly used, one item measure originated from the relationship evaluation questionnaire (RELATE; Busby et al. 2001) and identifies the occurrence of sexual activity within their relationship (e.g., Hill et al. 2017; McNulty and Fisher 2008; Willoughby et al. 2014). Sexual satisfaction was measured as a latent variable (4 items) using well-established measures (Busby et al. 2001) that examine the quality of sexual intimacy in the couple's relationship. These items examined how happy they were with various aspects of their sexual relationship. For example, the survey asked, "How satisfied are you with how often you currently have sex with your partner?" and "How satisfied are you with the amount of love and affection there is in your sexual relationship with your partner?" Responses on a Likert scale ranged from one (very unsatisfied) to five (highly satisfied). Supplemental Table $\mathrm{S} 1$ found in the online appendix provides more detail on the construction of all measures. We performed additional sensitivity on our measures by testing for measurement invariance following the process outlined by Widaman et al. (2010) as shown in Supplemental Table S2. Our measure of sexual satisfaction was strictly invariant across spouses and across time, as determined by a change in CFI less than 0.01 (Cheung and Rensvold 2002; Little 2013).

\section{Moderator Variables}

We used three sets of moderators to explore whether distinct forms of couple communication amended links between economic pressure and sexual outcomes. We used financial communication, a measure developed for the Emerging Adult Financial Capability Study (EAFCS; Jorgensen and Savla 2010), to explore how well couples communicated about finances and money. The survey asked, "How well are you and your spouse able to communicate about money?" with a range from one (not well at all/poor financial communication) to five (very well/strong financial communication). We used a latent construct to capture sexual communication (Busby et al. 2001; 2 items) to assess how well couples communicated about their sexual relationship. The survey asked respondents to rate the following: "I talk openly with my partner about our sexual relationship" and "We are able to 
Table 1 Summary statistics for demographic variables, sexual outcomes, forms of couple communication, and financial behaviors split by gender $(N=2044$ couples $)$

\begin{tabular}{|c|c|c|c|c|c|c|}
\hline & \multicolumn{3}{|l|}{ Wife } & \multicolumn{3}{|c|}{ Husband } \\
\hline & Mean & SD & Min-Max & Mean & SD & Min-Max \\
\hline Age (at Time 2) & 29.17 & 5.28 & $17-63$ & 29.96 & 5.92 & $16-63$ \\
\hline White & 0.63 & 0.48 & $0-1$ & 0.55 & 0.50 & $0-1$ \\
\hline Black & 0.08 & 0.28 & $0-1$ & 0.09 & 0.28 & $0-1$ \\
\hline Hispanic & 0.18 & 0.39 & $0-1$ & 0.13 & 0.33 & $0-1$ \\
\hline Age when married to current spouse & 26.68 & 5.04 & $15-50$ & 28.59 & 5.82 & $17-60$ \\
\hline Has been in a previous marriage & 0.08 & 0.27 & $0-1$ & 0.09 & 0.28 & $0-1$ \\
\hline T1 some college, no degree & 0.58 & 0.49 & $0-1$ & 0.52 & 0.50 & $0-1$ \\
\hline T2 some college, no degree & 0.54 & 0.50 & $0-1$ & 0.49 & 0.50 & $0-1$ \\
\hline T1 Bachelor's degree or more & 0.34 & 0.47 & $0-1$ & 0.26 & 0.44 & $0-1$ \\
\hline T2 Bachelor's degree or more & 0.33 & 0.47 & $0-1$ & 0.25 & 0.43 & $0-1$ \\
\hline T1 student status & 0.10 & 0.30 & $0-1$ & 0.08 & 0.27 & $0-1$ \\
\hline $\mathrm{T} 2$ student status & 0.07 & 0.25 & $0-1$ & 0.06 & 0.23 & $0-1$ \\
\hline $\mathrm{T} 1$ working full time & 0.40 & 0.49 & $0-1$ & 0.58 & 0.49 & $0-1$ \\
\hline $\mathrm{T} 2$ Working full time & 0.38 & 0.48 & $0-1$ & 0.55 & 0.50 & $0-1$ \\
\hline $\mathrm{T} 1$ currently pregnant & 0.08 & 0.27 & $0-1$ & - & - & - \\
\hline $\mathrm{T} 2$ ccurrently pregnant & 0.07 & 0.25 & $0-1$ & - & - & - \\
\hline $\mathrm{T} 1$ number of children & 0.84 & 1.19 & $0-8$ & - & - & - \\
\hline $\mathrm{T} 2$ number of children & 0.89 & 1.16 & $0-7$ & - & - & - \\
\hline $\mathrm{T} 1$ relationship satisfaction & 3.98 & 1.14 & $0-5.33$ & 4.01 & 1.09 & $0-5.25$ \\
\hline $\mathrm{T} 2$ relationship satisfaction & 3.91 & 1.16 & $0-5.33$ & 3.92 & 1.09 & $0-5.25$ \\
\hline T1 physical symptoms & 1.91 & 0.30 & $1-2.6$ & 1.94 & 0.27 & $1-2.6$ \\
\hline T2 physical symptoms & 1.90 & 0.28 & $1-2.6$ & 1.94 & 0.26 & $1-2.6$ \\
\hline $\mathrm{T} 1$ depressive symptoms & 2.00 & 0.48 & $1-4$ & 1.85 & 0.45 & $1-4$ \\
\hline $\mathrm{T} 2$ depressive symptoms & 2.00 & 0.46 & $1-4$ & 1.83 & 0.42 & $1-4$ \\
\hline $\mathrm{T} 1$ economic pressure & 2.52 & 0.98 & $1-5$ & 2.42 & 0.94 & $1-5$ \\
\hline $\mathrm{T} 2$ economic pressure & 2.48 & 0.97 & $1-5$ & 2.36 & 0.93 & $1-5$ \\
\hline T1 sexual frequency & 3.80 & 1.23 & $1-7$ & 3.83 & 1.23 & $1-7$ \\
\hline $\mathrm{T} 2$ sexual frequency & 3.70 & 1.22 & $1-7$ & 3.74 & 1.21 & $1-7$ \\
\hline T1 sexual satisfaction & 3.50 & 0.90 & $1-5$ & 3.43 & 0.84 & $1-5$ \\
\hline T2 sexual satisfaction & 3.50 & 0.93 & $1-5$ & 3.37 & 1.00 & $1-5$ \\
\hline $\mathrm{T} 2$ financial communication & 3.85 & 1.03 & $1-5$ & 3.91 & 1.00 & $1-5$ \\
\hline T2 sexual communication & 3.82 & 0.91 & $1-5$ & 3.76 & 0.91 & $1-5$ \\
\hline $\mathrm{T} 2$ relational communication & 3.94 & 0.73 & $1-5$ & 3.82 & 0.75 & $1-5$ \\
\hline
\end{tabular}

Economic pressure, sexual satisfaction, sexual communication, and relational communication were estimated as scales for this descriptive table. They were modeled as latent variables in the SEM model

$\dagger \mathrm{p}<0.1 . * \mathrm{p}<0.05$. ** $\mathrm{p}<0.01$ agree about what is acceptable in our sexual relationship." Responses ranged from one (never) to five (very often). We were unable to evaluate measurement invariance for sexual communication because there were not enough items for identification. We used a latent variable of relational communication (5 items) to assess overall communication skills. This scale was developed in the relationship evaluation questionnaire (RELATE; Busby et al. 2001) and continues to be used in research (e. g. Busby et al. 2010). Examples of information included in this scale include, "I am able to listen to my partner in an understanding way" and "My partner understands my feelings." Items were scaled to range from 1 (harmful relational communication) to 5 (healthy relational communication). We performed additional sensitivity on the relational communication items and found strict measurement invariance (see Supplemental Table S2).

\section{Independent Variables and Control Covariates}

We modeled our focal independent variable of economic pressure as a latent construct with four items. The scale was originally developed by Spilman and Burzette (2006) and adapted by the Flourishing Families project (Day et al. 2019). The survey asked respondents to rate statements 
like "I often worry about my financial situation" and "My financial situation is much worse this year than it was a year ago." Responses were reversed as needed and scaled to range from 1 (low stress) to 5 (high stress). The economic pressure measure was invariant across spouses and through time simultaneously, as demonstrated in Table S2.

Respondents self-reported demographic variables in Wave 1, unless otherwise noted. Demographic controls included age at the time of the first sample in years, race/ ethnicity, educational background (at Time 1 and Time 2), current student and employment status (at Time 1 and Time 2), family income (at Time 1 and Time 2), age at marriage to current spouse, previously married indicator, currently pregnant indicator (as reported by a wife at Time 1 and Time 2 ), and number of children (as reported by a wife at Time 1 and Time 2). In terms of additional covariates, we included a controls measuring relationship satisfaction at Time 1 and Time 2, considering that it was likely correlated with both communication and couple sexual outcomes. The relationship satisfaction measure for each time was constructed using four items from the Couples Satisfaction Index developed by Funk and Rogge (2007). On a scale from 0 (not at all) to 5 (completely), the scales asked questions of how satisfied couples were and how rewarding they found their relationships. We controlled for underlying physical health by measuring physical symptoms experienced over the past week at Time 1 and Time 2 . The physical symptoms checklist measured 13 areas of physical health and was developed by Larsen and Kasimatis (1991). Items were summed and higher scores reflected more physical symptoms. Finally, we controlled for mental health by assessing depressive symptoms at Time 1 and Time 2, using ten items from the Center for Epidemiologic Depression Scale developed by Andersen et al. (1994). Respondents reported on how often they experienced depressive symptoms such as loneliness and depression on a scale of 1 (rarely) to 7 (most or all of the time).

\section{Analytical Approach}

Bivariate correlation analysis tested associations between dependent variables (sexual frequency, satisfaction), moderators (financial communication, sexual communication, relational communication), and the independent variable (economic pressure). Inferences were made based on a critical value of 0.05 .

Longitudinal Confirmatory Factor Analysis with no moderation was performed so that economic pressure and sexual outcomes (frequency and satisfaction) predicted one another in accordance with our conceptual model and hypotheses. This model tested our first hypothesis. For those with missing values, data were not missing completely at random; minorities and less educated couples more often had missing values. After controlling for demographics it is reasonable to proceed assuming missing values were missing at random (MAR). We employed Full Information Maximum Likelihood (FIML) estimation to address missing values by estimating a likelihood function even with an incomplete data matrix (Johnson and Young 2011; Tagliabue and Donato 2015). The data had $27 \%$ of missing information, suggesting some likelihood that FIML will perform well during estimation (Allison 2001; Collins et al. 2001). FIML is always at least as good as using listwise deletion in an analysis, and often better (Graham 2009). Our model uses an actor-partner interdependence approach, allowing variables to connect with their own predictors as well as their partner's predictors (Kenny et al. 2006). The use of longitudinal CFA models allowed for simultaneous estimation of multiple relationships in a large model that accounted for correlations across dependent variables. Sexual frequency and sexual satisfaction for each partner at each time period were estimated as separate dependent variables. Economic pressure of each partner predicted sexual own and partner sexual outcomes contemporaneously and longitudinally. Although not explicitly shown in the conceptual model for parsimony, sexual outcomes at Time 1 also were used to predict outcomes in Time 2. Additionally, the analysis included all the demographic and couple characteristics described in the measures section as linear controls on all sexual measures and financial outcomes. To account for non-independence in data across endogenous variables, we correlated the error terms of items in latent variables across spouses and waves. We also correlated latent variables and all time varying measures across spouses and time.

We tested our second hypothesis with a moderation model which focused only on connections between $\mathrm{T} 2$ economic pressure and T2 sexual outcomes. We were unable to test longitudinal moderation due to a lack of data on communication measures prior to T2, and instead we used contemporaneous moderators. Therefore, the moderation model did not include $\mathrm{T} 1$ economic pressure or $\mathrm{T} 1$ sexual outcomes. A separate model was estimated for each moderation case, with six total moderation models estimated. While the probability of finding significant results increases when testing moderators separately, separate models were estimated, rather than one all-inclusive model, to avoid problems with multicollinearity and achieve model convergence. This is a known trade-off when estimating moderation using latent constructs rather than constructed scales.

To add moderators, we included communication main effects as well as communication by economic pressure interactions for both spouses. For example, the wife financial communication model for own sexual outcomes included interactions for a wife's financial communication (which moderated her own economic pressure and her partner's) with her own sexual outcomes. Interaction variables were centered at zero to eliminate any correlation with main 
effects. To account for non-independence in data across endogenous variables, we correlated the error terms of items in latent variables across spouses and waves. We also correlated latent variables across spouses. We included main effects of other forms of communication and all controls mentioned in the measures section to increase the likelihood that our results measured independent relationships rather than confounded factors.

To evaluate our third hypothesis, we tested for structural invariance in the longitudinal CFA model. First we tested for structural invariance in actor effects based on the change in the CFI generated by comparing an unconstrained model to a model constraining actor effects to be equal for husbands and wives. This test uses large changes in model fit in nested models to reject invariance (Kline 2011). Next, we tested for structural invariance on partner associations in the longitudinal model, again using a change in the CFI to detect changes in model fit. Because we were unable to test spouse moderators in the same moderation models, we were unable to evaluate structural invariance in the moderation models. In all analyses, we estimated using sample weights provided by the CREATE study to ensure the sample was nationally representative. Analyses were performed using Mplus 8.3. The study was approved by all related IRB boards.

\section{Results}

\section{Bivariate Correlations}

Table 2 reports bivariate correlations between economic pressure, sexual outcomes, and communication variables. Bivariate correlation analysis revealed strong concordance between partners on all measures. There were strong longitudinal positive correlations in economic pressure, including own and partner correlations. Similarly, we found longitudinal positive correlation for own and partner connections in sexual frequency and sexual satisfaction. We found strong contemporaneous negative correlations in $\mathrm{T} 1$ between economic pressure and sexual outcomes for actors. Additionally, we found negative partner effects between T1 husband's economic pressure and T1 wife's sexual outcomes, but did not see evidence of correlation between T1 wife's economic pressure and T1 husband's sexual outcomes. We found negative correlations between $\mathrm{T} 2$ economic pressure and $\mathrm{T} 2$ sexual outcomes for actors. We also found negative partner effects between T2 economic pressure and T2 sexual outcomes, with the exception of no correlation between T2 wife's economic pressure and T2 husband's sexual frequency.

Longitudinal correlations between economic pressure and sexual outcomes showed that T1 wife's economic pressure negatively correlated with sexual satisfaction for herself and her partner. Husband's economic pressure in T1 negatively correlated with his own sexual satisfaction and that of his partner, and higher T1 economic pressure of a husband correlated with lower sexual frequency for his wife in $\mathrm{T} 2$.

All forms of T2 couple communication positively correlated with $\mathrm{T} 2$ sexual frequency and $\mathrm{T} 2$ sexual satisfaction for both actors and partners. While correlations are important for demonstrating patterns observed in data before applying modeling frames, it is important to bear in mind that these correlations did not control for individual or couple characteristics or account for simultaneous effects. To more rigorously estimate effects, we turn now to confirmatory factor analysis modeling.

\section{Longitudinal Actor-Partner Interdependence Model}

Table 3 contains information from modeling and testing the first hypotheses regarding associations between economic pressure, the proposed independent variable, and sexual outcomes. In terms of model fit, the Chi-square fit statistic for the model was 26,888.00 with 1998 degrees of freedom and a $p$-value $<.001$. This suggests the model is not a good fit for the data. However, this test is overly sensitive to large sample sizes and its use as a fit statistic has recently come into question (Little 2013). We therefore relied on other fit metrics which indicate the model fit remains good overall with RMSEA $=.024$ (90\% confidence intervals of 0.022 and 0.025 ) and $\mathrm{CFI}=0.930$. The first panel shows associations between $\mathrm{T} 1$ economic pressure and $\mathrm{T} 1$ sexual outcomes. Wives' T1 sexual frequency was not associated with their own or their partners' T1 economic pressure. Husbands' $\mathrm{T} 1$ sexual frequency was negatively predicted by their own $\mathrm{T} 1$ economic pressure $(b=-.23, p=.003)$, and positively with their partner's T1 economic pressure $(b=.16, p=.043)$. We detected own effects of T1 economic pressure on $\mathrm{T} 1$ sexual satisfaction for wives $(b=-.17, p=.002)$, with no partner effects. Similarly, T1 sexual satisfaction for husbands negatively associated with their own $\mathrm{T} 1$ economic pressure $(b=-.18, p=.001)$ and positively associated with their partners' T1 economic pressure $(b=.21, p<.001)$. For husbands and wives, T2 sexual frequency did not associate with $\mathrm{T} 2$ own economic pressure or partner $\mathrm{T} 2$ economic pressure. Wives' T2 economic pressure predicted lower T2 own sexual satisfaction $(b=-.23, p<.001)$, and wives' T2 sexual satisfaction was not predicted by partner's economic pressure. Husbands T2 sexual satisfaction was negatively associated with $\mathrm{T} 2$ own economic pressure $(b=-.16$, $p=.045$ ) and was not associated with T2 partner economic pressure. Interestingly, the model predicted strong positive longitudinal connections for economic pressure, and also for sexual outcomes. We found some evidence of longitudinal connection between $\mathrm{T} 1$ economic pressure and $\mathrm{T} 2$ sexual outcomes for wives own connections. The marginally 


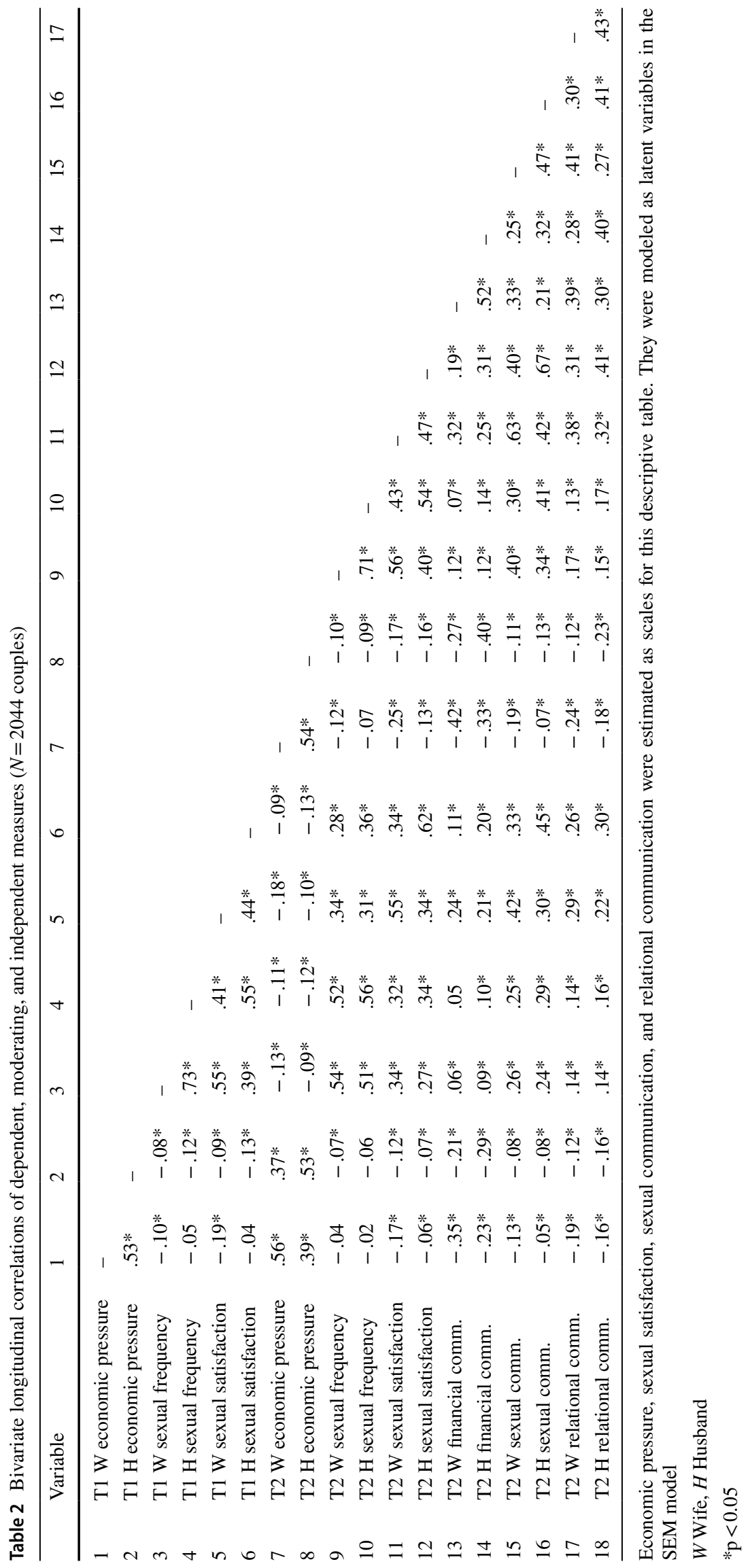


Table 3 Results for economic pressure predicting sexual frequency and sexual satisfaction without moderators $(N=2044$ couples $)$

\begin{tabular}{|c|c|c|c|c|c|c|c|c|}
\hline & \multicolumn{4}{|c|}{ T1 sexual frequency } & \multicolumn{4}{|c|}{ T1 sexual satisfaction } \\
\hline & \multicolumn{2}{|l|}{ Wife } & \multicolumn{2}{|l|}{ Husband } & \multicolumn{2}{|l|}{ Wife } & \multicolumn{2}{|l|}{ Husband } \\
\hline & $\mathrm{b}$ & SE & $\mathrm{b}$ & SE & $\mathrm{b}$ & SE & $\mathrm{b}$ & SE \\
\hline $\mathrm{T} 1 \mathrm{~W}$ economic pressure & -.05 & .07 & $.16^{*}$ & .07 & $-.17 * *$ & .06 & $.21 * * *$ & .06 \\
\hline \multirow[t]{4}{*}{ T1 H economic pressure } & .00 & .07 & $-.23 * *$ & .08 & .08 & .05 & $-.18 * * *$ & .06 \\
\hline & & \multicolumn{7}{|c|}{$\mathrm{T} 2$ economic pressure } \\
\hline & & \multicolumn{3}{|l|}{ Wife } & & \multicolumn{3}{|c|}{ Husband } \\
\hline & & $\mathrm{b}$ & & SE & & $\mathrm{B}$ & & SE \\
\hline $\mathrm{T} 1 \mathrm{~W}$ economic pressure & & $.59 * * *$ & & .07 & & .10 & & .07 \\
\hline \multirow[t]{4}{*}{$\mathrm{T} 1 \mathrm{H}$ economic pressure } & & .04 & & .06 & & $.52 * * *$ & & .07 \\
\hline & \multicolumn{4}{|c|}{$\mathrm{T} 2$ sexual frequency } & \multicolumn{4}{|c|}{ T2 sexual satisfaction } \\
\hline & \multicolumn{2}{|l|}{ Wife } & \multicolumn{2}{|l|}{ Husband } & \multicolumn{2}{|l|}{ Wife } & \multicolumn{2}{|l|}{ Husband } \\
\hline & $\mathrm{b}$ & SE & $\mathrm{B}$ & SE & $\mathrm{b}$ & SE & $\mathrm{b}$ & SE \\
\hline $\mathrm{T} 1 \mathrm{~W}$ economic pressure & $.20 *$ & .08 & .04 & .08 & $.16^{*}$ & .07 & -.07 & .08 \\
\hline $\mathrm{T} 1 \mathrm{H}$ economic pressure & -.10 & .08 & .02 & .08 & -.07 & .07 & .15 & .07 \\
\hline $\mathrm{T} 1 \mathrm{~W}$ sexual frequency & $0.28 * * *$ & .05 & $.23 * * *$ & .05 & -0.04 & .04 & .03 & .04 \\
\hline $\mathrm{T} 1 \mathrm{H}$ sexual frequency & $.30 * * *$ & .05 & $.34 * * *$ & .05 & $.09 *$ & .04 & -.01 & .03 \\
\hline T1 W sexual satisfaction & -.01 & .07 & -.11 & .07 & $.41 * * *$ & .06 & $-.14 *$ & .06 \\
\hline T1 H sexual Satisfaction & $-.13 *$ & .06 & .00 & .06 & -.07 & .05 & $.56 * * *$ & .06 \\
\hline $\mathrm{T} 2 \mathrm{~W}$ economic pressure & -.15 & .08 & .06 & .08 & $-.23 * * *$ & .07 & .05 & .08 \\
\hline $\mathrm{T} 2 \mathrm{H}$ economic pressure & -.04 & .08 & -.12 & .08 & -.05 & .07 & $-.16^{*}$ & .08 \\
\hline
\end{tabular}

Although the estimated model included demographic and couple covariates, this table does not report the coefficients on demographic and couple control covariates. Results including demographic and couple control covariates available on request. Model fit statistics indicate good fit: RMSEA $=.02, \mathrm{CFI}=0.93$

$* \mathrm{p}<0.05, * * \mathrm{p}<0.01, * * * \mathrm{p}<0.001$

significant longitudinal connection we found were between wives' $\mathrm{T} 1$ economic pressure and wives' $\mathrm{T} 2$ sexual frequency $(b=.20, p=.011)$ and wives' T2 sexual satisfaction $(b=.16, p=.026)$. There were no longitudinal connections for husbands own effects, and we found no longitudinal partner connections.

\section{Communication Moderators}

In order to test the second hypothesis of the study regarding the moderating role of forms of communication, three moderation models were tested. Because the model was estimated using maximum likelihood with robust errors, we could not assess fit of the model. We evaluated two outcomes per spouse, three moderators, two partners moderating an actor and a partner, and economic pressure for both partners, which created 48 cases to evaluate $(2 \times 3 \times 2 \times 2 \times 2)$. For brevity, we focus only on four cases where moderators were statistically significant at the 5\% level (results of other cases available upon request). The results of the moderation analyses are presented graphically in Fig. 3 using predicted values one standard deviation above the mean against predicted values one standard deviation below the mean.

\section{Wives' 12 Communication Moderating Wives' T2 Economic Pressure}

When wives experienced economic pressure, financial communication by wives protected the associations between economic pressure and sexual outcomes. Wives with strong financial communication maintained sexual satisfaction when they experienced economic pressure whereas wives with weak financial communication experienced lower sexual satisfaction during times of economic pressure (Fig. 3, first panel). This is illustrated by the relatively flat slope for wives with high financial communication and the steep negative slope for wives with low financial communication. 

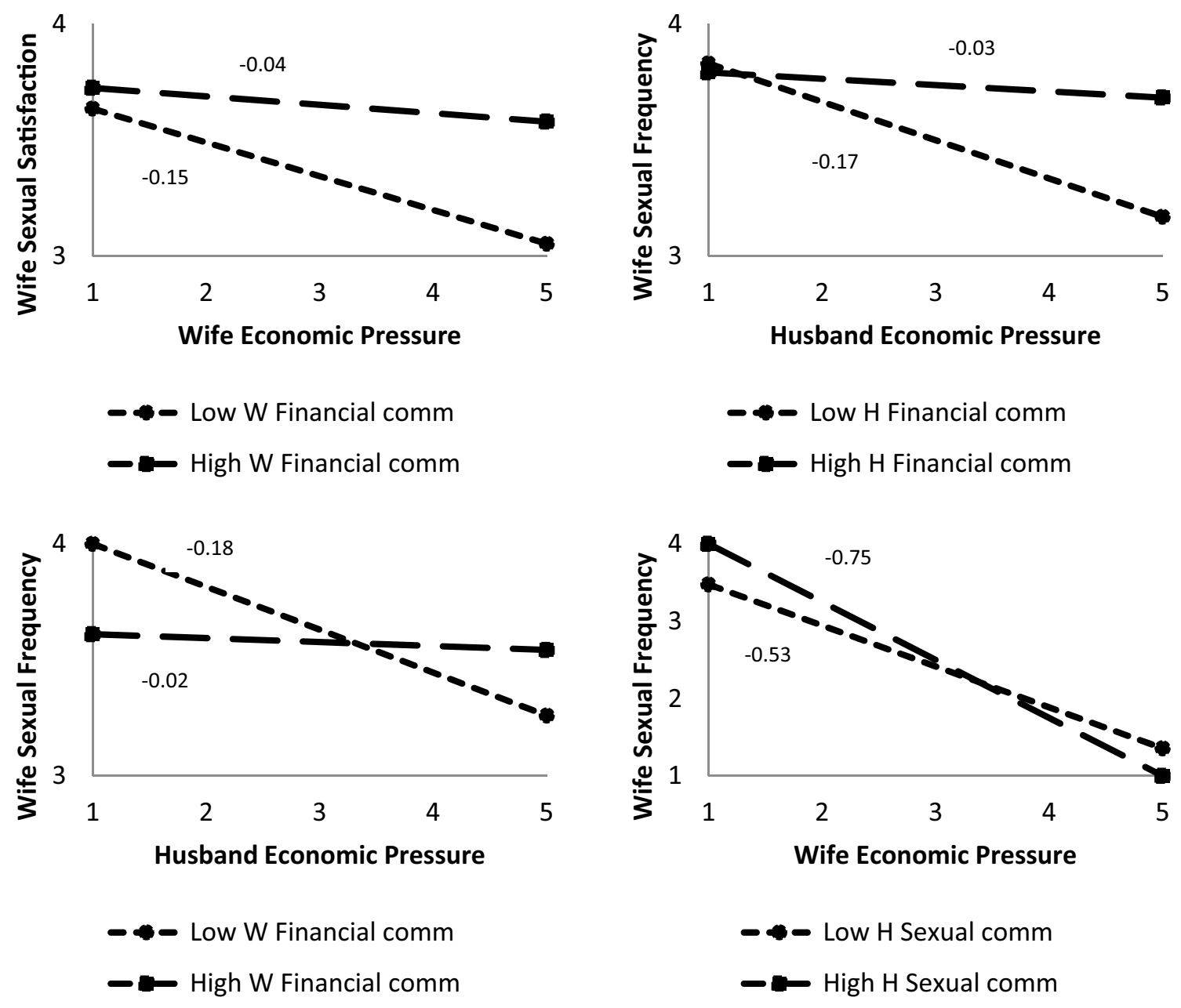

Fig. 3 Predicted sexual outcomes with communication moderating economic pressure on a spouse. \pm 1 SD as reference points for communication

\section{Husbands' T2 Communication Moderating Husbands' T2 Economic Pressure}

When husbands experience economic pressure, husbands with strong financial communication skills maintained their wives' sexual frequency (Fig. 3, second panel), as demonstrated by the flat slope on sexual frequency for husbands with strong financial communication compared to the negative slope for husbands with low financial communication.

\section{Wives' 12 Communication Moderating Husbands' T2 Economic Pressure}

Among wives with low financial communication we found a negative correlation between economic pressure and wives' sexual frequency, as demonstrated by the negative slope in the third panel of Fig. 3. On the other hand, there was little correlation between economic pressure and wives' sexual frequency when wives with high financial communication, as illustrated by the relatively flat slope in the third panel of Fig. 3.

\section{Husbands' T2 Communication Moderating Wives' Economic Pressure}

When wives experienced high economic pressure, wives' sexual frequency dropped more when husbands were strong sexual communicators and dropped less when husbands were weak at sexual communication (Fig. 2, fourth panel).

\section{Gendered Actor-Partner Associations}

To evaluate our third hypothesis on gender differences in associations, we tested for structural invariance across informants. As shown in Table 4, in the longitudinal model, we found structural invariance on the actor test and the partner test when using the change in CFI as the testing criteria. However, we failed to find structural invariance when using 
Table 4 Structural invariance test $(\mathrm{N}=2044$ couples $)$

\begin{tabular}{lllllllllll}
\hline & $d f$ & Log-likelihood & $\chi^{2}$ & CFI & $\Delta d f$ & $\begin{array}{c}\Delta \text { Log- } \\
\text { likelihood }\end{array}$ & $\Delta \chi^{2}$ & $\Delta$ CFI & Invariance? \\
\hline Longitudinal CFA model & 1543 & $-105,658.05$ & 3294.73 & 0.930 & & & & & \\
Own associations & 1556 & $-105,667.70$ & 3308.81 & 0.930 & 13 & 9.65 & 14.08 & 0.000 & $\mathrm{Y}$ \\
Partner associations & 1556 & $-105,665.66$ & 3305.04 & 0.930 & 13 & 7.61 & 10.31 & 0.000 & $\mathrm{Y}$ \\
\hline
\end{tabular}

Invariance tests were based on a change in $\mathrm{CFI} \leq 0.01$ (Kline 2011)

a likelihood ratio test. The disagreement between testing metrics suggests that although husbands and wives appear to have similar responses to economic pressure, more research is needed to confirm patterns.

\section{Discussion}

This study contributed to couple finance research by examining links between economic pressure and marital sexual outcomes, as well as the moderating roles of financial communication, sexual communication, and relational communication on those associations. One clear message is that contemporaneous sexual outcomes were generally sensitive to own economic pressure, providing partial support for our first hypothesis. This was true for husbands on sexual frequency, and both husbands and wives for sexual satisfaction. Our findings that both husbands and wives were sensitive to economic pressure are important, an important finding in the broader context of past work suggesting husbands were sensitive (Anand et al. 2008; Thoits 1987). Economic pressure appeared to have the most focused impact on the person experiencing economic pressure, providing a nuanced view of actor versus partner effects on sexual outcomes. Interestingly, partner connections were only present for husbands' sexual outcomes in $\mathrm{T} 1$ and were positive. This suggests economic pressure experienced by one spouse did not spill over into the other spouse's sexual outcomes in a negative way.

In terms of longitudinal links, we found no evidence that either husbands' or wives' economic pressure negatively influenced sexual outcomes through time. This result did not support our first hypothesis which posited negative longitudinal links between economic pressure and sexual outcomes. The consequences of economic pressure may decrease as couples learn to successfully manage and cope with the economic pressure they face, even if pressure levels or financial situations remain unchanged through time. Additionally, newlywed couples have a particularly high rate of change in their sexual relationship (McNulty et al. 2016), and this flexibility may be helpful in adjusting to economic pressure. While we found strong contemporaneous effects of economic pressure on sexual outcomes, negative effects were not detected the following year. This finding taken in context with past research on how long couples perceive financial effects (Papp et al. 2009) suggests that continually experiencing economic pressure may be the source of the perception that financial issues have longer-term effects. This perception of long-term effects may also be affected by an unexpected and dramatic change to newlyweds' initially optimistic predictions of the future after facing economic pressure (Lavner et al. 2013). Perhaps couples don't fully appreciate their ability to cope and adjust to those pressures over time. This finding provides hope to couples facing economic pressure. Couples can be confident that the economic pressure they feel at the time will not permanently affect their sexual relationship.

The evaluation of how different types of communication may help couples experiencing economic pressure has important implications. Economic pressure is correlated with negative communication in early marriage (Williamson et al. 2013) and poor financial communication among newlywed couples predicts greater sexual conflict for husbands leading to negative relationship outcomes for both husband and wives (Wheeler and Kerpelman 2016). However, when a partner experienced economic pressure, being a strong financial communicator protected wives' sexual outcomes from economic pressure. Wives also protected their own sexual outcomes by being good financial communicators when husbands had high economic pressure. We found less support for our third hypothesis, which posited that strong financial communication will protect wives and strong sexual communication will protect husbands from the negative consequences of economic pressure. Our findings suggest that strong financial communication was an asset to couples when husbands experienced economic pressure. Sexual outcomes improved for wives when the couple dealt with their economic pressure in the marriage using healthy financial communication. However, we note that good financial, sexual, or relational communication by either partner was not helpful in protecting husbands' sexual outcomes. The ability of communication to amend economic pressure for wives sexual outcomes and not husbands outcomes is particularly important in relation to the findings in other research that suggests husbands may be especially sensitive to the negative effects of economic pressure (Anand et al., 2008; Morokqff and Gillilland 1993; Thoits 1987). 
Interestingly, good communication by husbands was not helpful in protecting wives' sexual outcomes. In fact, when wives experienced high economic pressure, strong sexual communication from husbands harmed wives' sexual frequency whereas weaker sexual communication from husbands during these times protected sexual frequency. Our finding that partner communication was not helpful when women experienced economic pressure did not support our third hypothesis. These findings are surprising, considering research showing that women benefit in non-sexual domains by expressing their feelings about financial stress (Brougham et al. 2009). Future research may examine how economic pressure is felt by women and why sexual communication did not seem to alleviate the impact on sexual frequency. It may be that as women feel economic pressure, sexual desire is diminished. This gender difference requires additional study.

An important theme of this research is that healthy financial communication during times of economic pressure helped couples in non-financial domains. Couples struggle to talk about finances and avoid talking about the economic pressure they feel (Zmyslinski-Seelig 2016). However, our research suggests engaging in these difficult conversations may be one of the resources that allows couples to develop sexual intimacy as couples learn to communicate with each other about financial issues. Talking about economic pressure may provide support within a marriage as couples address financial issues together instead of allowing pressure to trouble them separately. These findings align with both the family stress model (Conger et al. 1994), FAAR (Patterson 2002), and previous findings (e.g., Conger et al. 1999). That is, communication may help couples adapt to negative financial events. Conger and et al. (1999) found similar results. Couples' mutual problem-solving abilities helped them avoid the marital distress that followed from feelings of economic pressure.

An interesting aspect of this research is the finding that financial communication protected sexual outcomes from economic pressure whereas relational and sexual communication did not. Past research (Litzinger and Gordon 2005) taken with our findings suggests relational communication operates independently from economic pressure. The distinctions in communication suggest that couples follow different scripts when engaging in each type of communication. Different forms of communication may accomplish different objectives. Romo (2015) suggested that communication may be a mechanism to reduce stress when experiencing economic pressure, leading to strengthened relationships. It may be that financial communication is a viable tool for affecting links between money and sex, whereas sexual communication or more general relational communication may be less effective.

\section{Limitations and Further Directions}

The study makes an important contribution in moving the couple finance literature in valuable ways, but even so, we acknowledge limitations of this research. The sample focused on transitions to marriage with at least one person in the couple entering a first marriage, resulting in a relatively young and selected sample of married couples. Couples often follow trajectories established early in marriage (Lavner et al. 2014), and our study of newlywed couples is likely relevant for couples who have been married for longer periods of time. Nonetheless, we suggest caution in generalizing results to other couples. More research is needed on couples who have been married for longer periods of time, cohabiting couples, and for previously married couples to understand whether patterns generalize or are unique to the marital transition. We provide this work as a descriptive portrait of associations found in our data and recognize the potential for selection concerns to limit our ability to make causal inferences. These concerns could be addressed in future research using a communication intervention in a randomized setting for couples experiencing economic pressure. More research is also needed to understand why certain forms of communication benefitted couples' sexual outcomes differently. Sexual communication and financial communication in particular are concepts that are only recently receiving research attention, and this research points to a need for the development of stronger sexual communication measures and financial communication measures. Nonetheless, we found an important role for financial communication.

Although our measures were based on scales used in prior research, the measures had not been validated, and the use of non-validated instruments remains a limitation of this research. We suggest future research using stronger validated measures of couple financial communication to determine if financial communication plays a larger role than we were able to detect due to data limitations on this measure. Future research could examine a more detailed and validated measure of sexual communication to better understand why sexual communication was not protective. Finally, due to data constraints, this study was unable to test a longitudinal moderation model. A longitudinal moderation model would provide information on the persistence of protective factors.

\section{Conclusion}

Despite limitations, this study found important concurrent connections between economic pressure and sexual outcomes for both husbands and wives. On the other hand, no negative longitudinal associations between economic pressure and sexual outcomes were found. The research 
highlighted the need to consider how actor and partner experiences in finances connect with couple sexual relationships and demonstrates that economic pressure affects couples, not simply individuals. This study has important applications for couples, family educators, and clinicians. Based on the findings of this study and other research (Hill et al. 2017), it is important for couples and clinicians to understand the value of healthy financial communication when a partner experiences economic pressure. Despite common hesitancy and even avoidance among many couples to have financial conversations, positive financial communication can act as a resource to protect against financial strain. Couples wanting to leverage positive financial communication can plan and prioritize financial conversations and encourage each other to move conversations beyond budgeting and logistics to include discussion of their economic pressure. Family life educators and financial therapists can teach couples approaches to build positive financial communication. This may strengthen sexual relationships by preparing couples to successfully navigate financial strain.

This study provides a more complete answer to the question of whether finances influence sex. We find that economic pressure is salient for a couple's sexual outcomes, especially during times of economic pressure. The study suggests that couples can navigate economic pressure by engaging in positive financial communication. While there is still much work to be done in understanding connections between money and sex, this study extends the field's understanding of how to protect couples from the negative effects of economic pressure on their sexual relationships.

Acknowledgements We acknowledge the CREATE project of the School of Family Life at Brigham Young University for sharing data for this project.

\section{References}

Allison, P. D. (2001). Missing data. Thousand Oaks, CA: Sage.

Andersen, E. M., Malmgren, J. A., Carter, W. B., \& Patrick, D. L. (1994). Screening for depression in well older adults: Evaluation of a short form of the CES-D. American Journal of Preventive Medicine, 10(2), 77-84. https://doi.org/10.1016/S9749 $-3797(18) 30622-6$

Anand, S. S., Islam, S., Rosengren, A., Franzosi, M. G., Steyn, K., Yusufali, A. H., et al. (2008). Risk factors for myocardial infarction in women and men: Insights from the INTERHEART study. European Heart Journal, 29, 932-940. https://doi.org/10.1093/ eurheartj/ehn018

Barton, A. W., \& Bryant, C. M. (2016). Financial strain, trajectories of marital processes, and African American newlyweds' marital instability. Journal of Family Psychology, 30(6), 657-664. https ://doi.org/10.1037/fam0000190

Bodenmann, G., Ledermann, T., Blattner-Bolliger, D., \& Galluzzo, C. (2006). The association between everyday stress, critical life events and sexual dysfunction. Journal of Nervous and Mental Disease, 194, 494-501.
Brougham, R. R., Zail, C. M., Mendoza, C. M., \& Miller, J. R. (2009). Stress, sex differences, and coping strategies among college students. Current Psychology, 28, 85-97. https://doi.org/10.1007/ s12144-009-9047-0

Busby, D. M., Carroll, J. S., \& Willoughby, B. J. (2010). Compatibility or restraint? The effects of sexual timing on marriage relationships. Journal of Family Psychology: Journal of the Division of Family Psychology of the American Psychological Association (Division 43), 24(6), 766-774. https://doi.org/10.1037/a0021690

Busby, D. M., Holman, T. B., \& Taniguchi, N. (2001). RELATE: Relationship evaluation of the individual, family, cultural, and couple contexts. Family Relations: An Interdisciplinary Journal of Applied Family Studies, 50(4), 308-316. https://doi.org/10.11 11/j.1741-3729.2001.00308.x

Chesney, A. P., Blackeney, P. E., Chan, M. S., \& Cole, C. M. (1981). The impact of sex therapy on sexual behaviors and marital communication. Journal of Sex \& Marital Therapy, 7, 70-79. https:// doi.org/10.1080/00926238108403440

Cheung, G. W., \& Rensvold, R. B. (2002). Evaluating goodness-of-fit indexes for testing measurement invariance. Structural Equation Modeling, 9, 233-255.

Collins, L. M., Schafer, J. L., \& Kam, C.-M. (2001). A comparison of inclusive and restrictive strategies in modern missing data procedures. Psychological Methods, 6, 330-351. https://doi. org/10.1037//1082-989X.6.4.330

Conger, R. D., Ge, X. J., \& Lorenz, F. O. (1994). Economic stress and marital relationships. In R. D. Conger \& G. H. Elders (Eds.), Families in troubled times (pp. 187-203). New York, NY: Walter de Gruyter.

Conger, R. D., Lorenz, F. O., Elder, G. H., Jr., Simons, R. L., \& Ge, X. (1993). Husband and wife differences in response to undesirable life events. Journal of Health and Social Behavior, 34(1), 71-88. https://doi.org/10.2307/2137305

Conger, R. D., Rueter, M. A., \& Elder, G. H., Jr. (1999). Couple resilience to economic pressure. Journal of Personality and Social Psychology, 76, 54-71. https://doi.org/10.1037/0022-3514.76.1.54

Day, R. D., Bean, R., Coyne, S., Dyer, J., Harper, J., \& Walker, L. (2019). Flourishing families project, combined codebook, waves I-IX. Provo, UT: School of Family Life, Brigham Young University.

Dean, L. R., Carroll, J. S., \& Yang, C. (2007). Materialism, perceived financial problems, and marital satisfaction. Family and Consumer Sciences Research Journal, 35, 260-281. https://doi. org/10.1177/1077727X06296625

del Mar Sánchez-Fuentes, M., Santos-Iglesias, P., \& Sierra, J. C. (2014). A systematic review of sexual satisfaction. International Journal of Clinical and Health Psychology, 14(1), 67-75.

Dew, J. P. (2007). Two sides of the same coin? The differing roles of assets and consumer debt in marriage. Journal of Family and Economic Issues, 28, 89-104. https://doi.org/10.1007/s1083 4-006-9051-6

Dew, J., \& Dakin, J. (2011). Financial disagreements and marital conflict tactics. Journal of Financial Therapy, 2(1), 23-42. https:// doi.org/10.4148/jft.v2i1.1414

Dew, J. P., LeBaron, A., \& Allsop, D. (2018). Can stress build relationships? Predictors of increased marital commitment resulting from the 2007-2009 recession. Journal of Family and Economic Issues, 39, 405-421. https://doi.org/10.1007/s10834-018-9566-7

Dew, J. P., \& Jackson, M. (2017). Commitment and relationship maintenance behaviors as marital protective factors during economic pressure. Journal of Family and Economic Issues, 39, 191-204. https://doi.org/10.1007/s10834-017-9550-7

Fox, J. J., \& Bartholomae, S. (2000). Economic stress and families. In C. A. Price, K. R. Bush, \& S. J. Price (Eds.), Families \& change-Coping with stressful events and transitions (2nd ed., pp. 250-271). New York, CA: Sage Publications Inc. 
Frederick, D. A., Lever, J., Gillespie, B. J., \& Garcia, J. R. (2017). What keeps passion alive? Sexual satisfaction is associated with sexual communication, mood setting, sexual variety, oral sex, orgasm, and sex frequency in a national US study. Journal of Sex Research, 54(2), 186-201. https://doi.org/10.1080/00224 499.2015.1137854

Funk, J. L., \& Rogge, R. D. (2007). Testing the ruler with item response theory: Increasing precision of measurement for relationship satisfaction with the Couples Satisfaction Index. Journal of Family Psychology, 21(4), 572-583. https://doi. org/10.1037/0893-3200.21.4.572

Garcia, R. L., Kenny, D. A., \& Ledermann, T. (2015). Moderation in the actor-partner inderdependence model. Personal Relationships, 22(1), 8-29. https://doi.org/10.1111/pere. 12060

Gottman, J. M., Coan, J., Carrere, S., \& Swanson, C. (1998). Predicting marital happiness and stability from newlywed interactions. Journal of Marriage and Family, 60(1), 5-22. https://doi. org $/ 10.2307 / 353438$

Graham, J. W. (2009). Missing data analysis: Making it work in the real world. Annual Review of Psychology, 60, 549-576. https:// doi.org/10.1146/annurev.psych.58.110405.085530

Gudmunson, C. G., Beutler, I. F., Israelsen, C. L., McCoy, J. K., \& Hill, E. J. (2007). Linking financial strain to marital instability: Examining the roles of emotional distress and marital interaction. Journal of Family and Economic Issues, 28, 357-376. https://doi. org/10.1007/s10834-007-9074-7

Haning, R. V., O’Keefe, S. L., Randall, E. J., Kommor, E. J., Baker, E., \& Wilson, R. (2007). Intimacy, orgasm likelihood, and conflict predict sexual satisfaction in heterosexual male and female respondents. Journal of Sex \& Marital Therapy, 33(2), 93-113. https://doi.org/10.1080/00926230601098449

Hill, E. J., Allsop, D. B., LeBarron, A. B., \& Bean, R. A. (2017). How does money, sex, and stress influence marital instability? Journal of Financial Therapy, 8, 2-42. https://doi. org/10.4148/1944-9771.1135

Huston, T. L., Caughlin, J. P., Houts, R. M., Smith, S. E., \& George, L. J. (2001). The connubial crucible: Newlywed years as predictors of marital delight, distress, and divorce. Journal of Personality and Social Psychology, 80(2), 237-252. https://doi. org/10.1037/0022-3514.80.2.237

Johnson, D. R., \& Young, R. (2011). Toward best practices in analyzing datasets with missing data: Comparisons and recommendations. Journal of Marriage and Family, 73(5), 926-945. https://doi.org /10.1111/j.1741-3737.2011.00861.x

Jorgensen, B. L., \& Savla, J. (2010). Financial literacy of young adults: The importance of parental socialization. Family Relations, 59(4), 465-478. https://doi.org/10.1111/j.1741-3729.2010.00616.x

Kenny, D. A., Kashy, D. A., \& Cook, W. L. (2006). Dyadic data analysis. New York, NY: Guilford Press.

Kline, R. B. (2011). Principles and practice of structural equation modeling (3rd ed.). New York, NY: Guilford Press.

Kwon, H., Rueter, M. A., Lee, M., Koh, S., \& Ok, S. W. (2003). Marital relationships following the Korean economic crisis: Applying the family stress model. Journal of Marriage and Family, 65, 316-325. https://doi.org/10.1111/j.1741-3737.2003.00316.x

LaMotte, A. D., Khalifian, C. E., \& Barry, R. A. (2017). Newlyweds' perceptions of partner conflict behaviors and change in intimate safety over time. Journal of Family Psychology, 31(1), 123-138. https://doi.org/10.1037/fam0000244

Larsen, R. J., \& Kasimatis, M. (1991). Day-to-day physical symptoms: Individual differences in the occurrence, duration, and emotional concomitants of minor daily illnesses. Journal of Personality, 59(3), 387-423. https://doi.org/10.1111/1467-6494.ep91101418 06

Larson, J. H., Anderson, S. M., Holman, T. B., \& Niemann, B. K. (1998). A longitudinal study of the effects of premarital self-disclosure, relationship stability, and self-esteem on sexual satisfaction in the first year of marriage. Journal of Sex and Marital Therapy, 24, 193-206. https://doi.org/10.1080/00926 239808404933

Lau, J. T., Kim, J. H., \& Tsui, H. Y. (2005). Mental health and lifestyle correlates of sexual problems and sexual satisfaction in heterosexual Hong Kong Chinese population. Urology, 66(6), 1271-1281. https://doi.org/10.1016/j.urology.2005.06.093

Laurenceau, J., Barrett, L. F., \& Rovine, M. J. (2005). The interpersonal process model of intimacy in marriage: A daily-diary and multilevel modeling approach. Journal of Family Psychology, 19(2), 314-323. https://doi.org/10.1037/0893-3200.19.2.314

Lavner, J. A., \& Bradbury, T. N. (2010). Patterns of change in marital satisfaction over the newlywed years. Journal of Marriage and Family, 72(5), 1171-1187. https://doi.org/10.111 1/j.1741-3737.2010.00757.x

Lavner, J. A., Karney, B. R., \& Bradbury, T. N. (2013). Newlyweds' optimistic forecasts of their marriage: For better or for worse? Journal of Family Psychology, 27(4), 531-540. https://doi. org/10.1037/a0033423

Lavner, J. A., Karney, B. R., \& Bradbury, T. N. (2014). Relationship problems over the early years of marriage: Stability or change? Journal of Family Psychology, 28, 979-985. https:// doi.org/10.1037/a0037752

Leavitt, C. E., Dew, J. P., Allsop, D. B., Runyan, S. D., \& Hill, E. J. (2019). Relational and sexual costs of materialism in couple relationships: An actor-partner longitudinal study. Journal of Family and Economic Issues, 40, 438-454. https://doi. org/10.1007/s10834-019-09617-3

Little, T. D. (2013). Longitudinal structural equation modeling. New York, NY: The Guildford Press.

Litzinger, S., \& Gordon, K. C. (2005). Exploring relationships among communication, sexual satisfaction and marital satisfaction. Journal of Sex \& Marital Therapy, 31, 409-424. https ://doi.org/10.1080/00926230591006719

MacNeil, S., \& Byers, E. S. (2009). Role of sexual self-disclosure in the sexual satisfaction of long-term heterosexual couples. Journal of Sex Research, 46(1), 3-14. https://doi.org/10.1080/00224 490802398399

Mark, K. P., \& Jozkowski, K. N. (2013). The mediating role of sexual and nonsexual communication between relationship and sexual satisfaction in a sample of college-age heterosexual couples. Journal of Sex \& Marital Therapy, 39(5), 410-427. https://doi. org/10.1080/0092623X.2011.644652

Markman, H. J., Renick, M. J., Floyd, F. J., Stanley, S. M., \& Clements, M. (1993). Preventing marital distress through communication and conflict management training: A 4-and 5-year follow up. Journal of Consulting and Clinical Psychology, 61, 70-77. https://doi.org/10.1037/0022-006X.61.1.70

McNulty, J. K., \& Fisher, T. D. (2008). Gender differences in response to sexual expectancies and changes in sexual frequency: A short-term longitudinal study of sexual satisfaction in newly married couples. Archives of Sexual Behavior, 37(2), 229-240. https://doi.org/10.1007/s10508-00709176-1

McNulty, J. K., Wenner, C. A., \& Fisher, T. D. (2016). Longitudinal associations among relationship satisfaction, sexual satisfaction, and frequency of sex in early marriage. Archives of Sexual Behavior, 45, 85-97. https://doi.org/10.1007/s1050 8-014-0444-6

Metz, M. E., \& Epstein, N. (2002). Assessing the role of relationship conflict and in sexual dysfunction. Journal of Sex and Marital Therapy, 28, 139-164. https://doi.org/10.1080/009262302528518 89

Montesi, J. L., Fauber, R. L., Gordon, E. A., \& Heimburg, R. G. (2010). The specific importance of communicating about sex to couples' sexual and overall relationship satisfaction. Journal of 
Social and Personal Relationships, 28(5), 591-609. https://doi. org/10.1177/0265407510386833

Morokqff, P. J., \& Gillilland, R. (1993). Stress, sexual functioning, and marital satisfaction. Journal of Sex Research, 30(1), 43-53. https://doi.org/10.1080/00224499309551677

Papp, L. M., Cummings, E. M., \& Goeke-Morey, M. C. (2009). For richer, for poorer: Money as a topic of marital conflict in the home. Family Relations, 58, 91-103. https://doi.org/10.111 1/j.1741-3729.2008.00537.x

Patterson, J. M. (2002). Integrating family resilience and family stress theory. Journal of Marriage and Family, 64, 349-360. https://doi.org/10.1111/j.1741-3737.2002.00349.x

Randles, J. M. (2014). Partnering and parenting in poverty: A qualitative analysis of a relationship skills program for low-income, unmarried families. Journal of Policy Analysis and Management, 33(2), 385-412. https://doi.org/10.1002/pam.21742

Rehman, U. S., Rellini, A. H., \& Fallis, E. (2011). The importance of sexual self-disclosure to sexual satisfaction and functioning in committed relationships. The Journal of Sexual Medicine, 8(11), 3108-3115. https://doi.org/10.1111/j.1743-6109.2011.02439.x

Romo, L. K. (2013). “These aren't very good times”: Financial uncertainty experienced by romantic partners in the wake of an economic downturn. Journal of Family and Economic Issues, 35(4), 477-488. https://doi.org/10.1007/s10834-014-9389-0

Romo, L. K. (2015). An examination of how people in romantic relationships use communication to manage financial uncertainty. Journal of Applied Communication Research, 43, 315-335. https://doi.org/10.1080/00909882.2015.1052831

Rook, K., Dooley, D., \& Catalano, R. (1991). Stress transmission: The effects of husbands' job stressors on the emotional health of their wives. Journal of Marriage and Family, 53(1), 165-177. https://doi.org/10.2307/353141

Ross, D. B., O’Neal, C. W., Arnold, A. L., \& Mancini, J. A. (2017). Money matters in marriage: Financial concerns, warmth, and hostility among military couples. Journal of Family and Economic Issues, 38, 572-581. https://doi.org/10.1007/s1083 4-017-9522-y

Skogrand, L., Johnson, A. C., Horrocks, A. M., \& DeFrain, J. (2011). Financial management practices of couples with great marriages. Journal of Family and Economic Issues, 32, 27-35. https ://doi.org/10.1007/s10834-010-9195-2

Spilman, S. K., \& Burzette, R. G. (2006). Critical transitions project technical reports, F10 2003. Ames, IA: Family Transitions Project, Iowa State University.

Tagliabue, S., \& Donato, S. (2015). Missing data in family research: Examining different levels of missingness. Testing, Psychometrics, Methodology in Applied Psychology, 22(2), 199-217. https ://doi.org/10.4473/TPM22.2.3

Thoits, P. A. (1987). Gender and marital status differences in control and distress: Common stress versus unique stress explanations. Journal of Health and Social Behavior, 28, 7-22. https://doi. org/10.2307/2137137

Timmons, A. C., Arbel, R., \& Margolin, G. (2017). Daily patterns of stress and conflict in couples: Associations with marital aggression and family-of-origin aggression. Journal of Family Psychology, 31(1), 93-104. https://doi.org/10.1037/fam0000227

Wheeler, B., \& Kerpelman, J. (2016). Change in disagreements about money, time, and sex and marital outcomes. Journal of Relationships Research, 7, 1-14. https://doi.org/10.1017/jrr.2016.8

Widaman, K. F., Ferrer, E., \& Conger, R. D. (2010). Factorial invariance within longitudinal structural equation models: Measuring the same construct across time. Child Development Perspectives, 4(1), 10-18.

Williamson, H. C., Karney, B. R., \& Bradbury, T. N. (2013). Financial strain and stressful events predict newlyweds' negative communication independent of relationship satisfaction. Journal of
Family Psychology, 27(1), 65-75. https://doi.org/10.1037/a0031 104

Williamson, H. C., \& Lavner, J. A. (2019). Trajectories of marital satisfaction in diverse newlywed couples. Social Psychological and Personality Science. https://doi.org/10.1177/1948550619 865056

Willoughby, B. J., Farero, A. M., \& Busby, D. M. (2014). Exploring the effects of sexual desire discrepancy among married couples. Archives of Sexual Behavior, 43(3), 551-562. https://doi. org/10.1007/s10508-013-0181-2

Wilmarth, M. J., Nielsen, R. B., \& Futris, T. G. (2014). Financial wellness and relationship satisfaction: Does communication mediate? Family and Consumer Sciences Research Journal, 43(2), 131-144. https://doi.org/10.1111/fcsr.12092

Yoo, H., Bartle-Haring, S., Day, R. D., \& Gangamma, R. (2014). Couple communication, emotional and sexual intimacy, and relationship satisfaction. Journal of Sex \& Marital Therapy, 40(4), 275-293. https://doi.org/10.1080/0092623X.2012.75107 2

Yorgason, J. B., James, S. L., \& Holmes, E. K. (2018). Couple relationships and transition experiences (CREATE) codebook (wave 1). Provo, UT: School of Family Life, Brigham Young University.

Zimmerman, K. J., \& Roberts, C. W. (2012). The influence of a financial management course on couples' relationship quality. Journal of Financial Counseling and Planning, 23(2), 46-54.

Zmyslinski-Seelig, A. N. (2016). To each their own: Comparing satisfaction, money management, and financial communication across couple types (Doctoral dissertation). Retrieved December 3, 2019 from https://dc.uwm.edu/cgi/viewcontent.cgi?artic le $=2243 \&$ context $=$ etd

Publisher's Note Springer Nature remains neutral with regard to jurisdictional claims in published maps and institutional affiliations.

Jocelyn S. Wikle is an Assistant Professor in the School of Family Life at Brigham Young University. Her research explores interactions in families, including the study of couple dynamics. She also researches parent investments in children in a variety of contexts, including family dinner, family leisure, family size, and patterns of parental investments in adoptive families. Her policy research evaluates the effects of early childhood education policy on family members of preschool children. Dr. Wikle has expertise in quantitative research methods. Dr. Wikle received her $\mathrm{PhD}$ in economics from the University of Texas at Austin.

Chelom E. Leavitt is an Assistant Professor at Brigham Young University in the School of Family Life. She received her PhD from Penn State. Her research focuses on sexuality within committed relationship and specifically being mindful during sexual experiences. Her recent research includes studies on crosscultural differences in sexual mindfulness, changes in sexual mindfulness after an intervention, and how materialism may be linked to sexual satisfaction.

Jeremy B. Yorgason is a Professor in the School of Family Life and Director of the Gerontology Program at Brigham Young University. His research interests include later life family relationships, with an emphasis on dyadic coping with illness. Dr. Yorgason received his PhD from Virginia Tech University in human development, and was a post-doctoral fellow at the Gerontology Center of Pennsylvania State University.

Jeffrey P. Dew is an Associate Professor in the School of Family Life at Brigham Young University. He teaches family theory, family finance, and graduate statistics courses. Dr. Dew's research focuses on the "daily 
life" issue of the association between family resources (i.e., money and time) and relationship quality. Examples of Dr. Dew's recent projects include examining factors that protect couples' marital quality during financial difficulties, and a qualitative strengths-based analysis of how African American couples talk about the role of finances in their marriage. Dr. Dew is a fellow of the Wheatley Institution.
Heather M. Johnson is a recent graduate from the School of Family Life with an emphasis in Family Studies at Brigham Young University. Her research interests include the impact of sexual communication on couple and family relationships, particularly on the parent-child relationship. 